\title{
Transportation: The un-slayed dragon in sugarcane farming in Western Kenya
}

\section{Mukhwana Duncan}

Department of History, Political Science \& Public Administration, Faculty of Arts and Social Sciences, Moi University, Kenya.

Accepted 1 December, 2020

\begin{abstract}
In Kenya, sugarcane farming was introduced in 1902 milled by jaggeries before the introduction of Miwani sugar factory in 1922 and Ramisi in 1927. In western Kenya, sugarcane farming was introduced in 1972, with the establishment of Mumias sugar company which produced its first sugar in 1973. Nzoia sugar company was then established in 1978 with its first production in 1979. Thereafter, private sugar companies were established in the area including: West Kenya sugar company, Butali sugar company, Busia sugar company and Ole Pito sugar. The expansion of sugarcane farming to the former western province targeted accelerating the socio-economic development in the area, in the quest to redress the region's economic imbalances through promoting indigenous entrepreneurship. Out of the total fourteen sugar factories in the country, six are currently domiciled and operating in the former western province. Despite the heavy presence of the sugar factories in the region, which marks a significant milestone in the industrialization direction, both farmers and sugar factories' self-sufficiency is an elusive dream. This is the situation despite the region's availability of both adequate and productive land for sugarcane farming and the heavy presence of adequate sugarcane milling capacity. This has prompted the study into what is necessitating the farmers' rapid desertion of sugarcane farming (the sugarcane withdrawal syndrome) in the former western province. The study concluded that the rapid desertion of sugarcane farming by farmers in western Kenya is attributable to the reality that transportation of their produce (sugarcane) whether private or contacted, exorbitantly depleted their net returns leaving the sugarcane farmers a frustrated lot with no option than to ditch sugarcane farming for alternative productions.
\end{abstract}

Keywords: Transportation, sugarcane, harvesting, remunerations and deductions.

E-mail mukangaiduncan@gmail.com, owawerukha@gmail.com. Tel: +254724783300.

\section{INTRODUCTION}

Globally, Brazil, India, China, Thailand and Pakistan are the leading sugarcane producers (Walton, 2020), while in Africa, South Africa, Egypt, Kenya, Zambia and Uganda are the leading countries (knoema.com, 2018). Sugarcane Transportation is one of the major problems for the global sugar industry. The loss of opportunity to produce sugar increases with the waiting time of the sugarcane before transportation limiting farmers' financial resource returns in the sugar industry (Higgins and Muchow, 2003; Diaz and Perez, 2000). This study aimed to study how transportation of sugarcane has threatened the farmers returns by claiming the lion share of the deductions from their net pay in western Kenya.
Sugarcane harvesting and transportation are twin processes which possess huge logistical operations world over in the sugar economy. Leading sugar producing countries like Cuba and Brazil transport their harvested sugarcane by both road and railway (www.allafrica.com/modules/canetransportation). To respond to sugarcane transportation needs quickly and satisfactorily with reasonable cost, the management of the sugarcane logistics and supply chain has a crucial role in creating advantages in a competitive business world (Hansen et al., 1998). However, in Africa and more so Kenya, there are still persistent problems in terms of managing the sugarcane logistics, harvesting and 
transport that can accommodate various region where sugarcane is harvested in the continent. As a result, the efficiency of the processes especially sugarcane transportation still remains low, with high costs for harvest and transportation in Kenya.

Sugarcane harvesting using a cutting machine is an approach that resolves the labor shortage in leading sugar producing countries (Muchow et al., 1998). In Brazil, India, China, Thailand, Pakistan among others, the sugarcane cutting machine harvests, then transport into sugarcane trucks running parallel with the harvesters on the farms for effective transportation. This study purposes to show how transport costs have eaten into the farmers returns yet neither the transporters nor the sugar factories compensate the sugarcane spillages on the roads in western Kenya. The cost of sugarcane harvesting and transportation constitutes a significant portion of the total sugarcane production cost. In order to reduce the total cost, it is necessary to re-work the current shortcomings of the harvesting and transportation processes. This should be carefully planned and coordinated to avoid the wastage of the harvested sugarcane. Consequently, long delays between harvesting and transportation of the sugarcane leads to deterioration in the quantities of sugarcane delivered to the sugar factories.

Efficient production of sugar from sugarcane requires integration of growing, harvesting, transport, milling, and marketing (Van Vliet et al., 1992). While researches targeted to each of these sectors have added significant value in the past in Kenya, further gains are limited, giving rise to an increasing focus on whole of systems research for the industry to maintain its international competitiveness. A major whole of industry issue in Kenya is the need to take advantage of geographical, temporal, and crop characteristic differences in sugarcane yields. Through capturing the sugarcane transportation variable, a farmers' documents analysis methodology was adopted that allowed the assessment of profitability benefits from the harvested sugarcane throughout the western Kenya region. In this study, transportation devices used for transporting sugarcane from the farms to sugar factories included 10 wheeltrucks, tractors, and cane dump carts. This paper focuses on an important practical and theoretical problem: where, when and how the retrieval of sugarcane from the farms to sugar factories has minimized farmers returns.

\section{THE PLACE OF SUGARCANE FARMING IN KENYA'S ECONOMY}

The agricultural sector in Kenya is the major engine of Kenya's economy and it predominantly supports over 80 percent of households in the country. The agricultural sector directly injects 26 percent to the country's Gross Domestic Product and an indirect additional 25 percent through agricultural chains and linkages, companies and industries, making the agricultural sector the backbone of Kenya's economy (Heyer et al., 1976). Within the agricultural sector, the sugar sub-sector provides rural employment opportunities among peasant households, guarantees food security and sustainability as well as sugarcane farmers private and collective economic development which consolidate in farmers' households improved livelihoods (Makana, 2008; Mukhwana, 2013; Barclay, 1997). According to the sugar taskforce report (2019), the sugar sector supports over 8 million people in Kenya directly and it is a source of income for more than 400,000 sugarcane peasant farmers mostly concentrated in the former western province region. The peasant sugarcane farmers produce more than 90 percent of the sugarcane processed into sugar in the country (Mukhwana, 2013). This explains why peasant farmers in Kenya are the beckons on which Kenya's big four agenda are hinged, primarily as the propellers of the manufacturing sector and as the facilitators of food security, sustainability and nutrition.

\section{GENERAL OVERVIEW OF THE PROBLEMS FACING SUGARCANE FARMING IN WESTERN KENYA}

On the overall, sugarcane farming in the former western province is currently facing multiple, complex and intertwined problems, despite guaranteeing food security and sustainability. The sugarcane farmers' problems range from the exorbitant cost of sugarcane production, high debts incurred from the anticipated sugarcane returns, sugar companies inefficiencies in handling the sugarcane produce, declining yield per unit of production area, complete absence of agricultural extension officers, absence/miss out on the benefitting from the proceeds of the sugarcane value addition products, to minimum (if any) incomes to farmers from their sugarcane production venture (Sugar Taskforce Report, 2019; Mukhwana, 2013).

With these complex and intertwined sugarcane farming problems, sugarcane farming is witnessing a rapidly declining trend in both the surface area under sugarcane production and the quantity as well as the quality of sugarcane produced. These in essence have threatened the sustainability of both sugarcane production and the sugar production in western Kenya. In the cases of Mumias sugar company and Nzoia sugar company for example, the 'death' of the farmers' out-grower wing exposed sugarcane farmers to the sugar company vagaries that minimize sugarcane farmers' negotiation power in bargaining with the sugar companies on the sugarcane cost as well as the cost for inputs and transportation of the produce to the company (Mukhwana, 2013; Chege, 2005; Butunyi and Otieno, 2009). The sugarcane farmers' situation is compounded by deliberate delayed payments even after they struggled to deliver the sugarcane produce to the companies. This created room for sugarcane brokers between the sugar 
companies and the farmers (Sugar Taskforce Report, 2019) which makes the sugarcane farmers even lose out more on their sugarcane produce returns. In reality, the sugarcane farmers have limited (if any), resources to replough into the subsequent sugarcane crops and when the frustrations set in due to the sugarcane farmers' inability to tend a good quality crop, they abandon completely sugarcane farming (Butunyi and Otieno, 2009). In instances where the sugarcane farmers are able to tend successfully a subsequent crop, the sugarcane farmers then redirect their sugarcane produce to a different sugar company[side-selling] (Mukhwana and Chang'ach, 2017), in many cases private sugar companies which pay promptly. But, because the private sugar companies know the sugarcane farmers' desperations, they end up buying the farmers' sugarcane at unfairly low prices for the farmers are never involved in the process of determining the unit costing of their produce (Sugar Taskforce Report, 2019). For the private sugar companies like Butali and West Kenya Sugar, a contemporary problem is the issuance of permits for sugarcane harvesting. The issuance of sugarcane harvesting permits in the said sugar companies is a den of corruption (Sugar Taskforce Report, 2019), with those ready to part with a coin getting their sugarcane harvested. This has put sugarcane harvesting in the hands of the petty bourgeoisie/large-scale sugarcane producers to the disadvantage of the majority peasant sugarcane farmers. The peasants with no parting coin risk late harvesting of their sugarcane, which partially accounts for low tonnage for their aged sugarcane. These, demotivates an already demoralized sugarcane farmer who's only remaining option is to quit sugarcane farming. By its nature, sugarcane production in western Kenya is cyclical, where a farmer harvests several harvests from the initial plant and this to a large extent explains the wide spread farmer apathy which is compounded by unsuitable sugarcane seed varieties which results in declining yields.

\section{SUGARCANE HARVESTING AND TRANSPORTATION IN WESTERN KENYA}

Sugarcane harvesting and transportation are a co-joint twin process which portent huge logistical operations world over in the sugarcane farming economy. Lead sugarcane producing countries like Cuba and Brazil transport their harvested sugarcane by both road and railway (Mukhwana, 2013). For Kenya and specifically the western Kenya sugar belt, the former mode is the sole form of transportation used to transport the harvested sugarcane to the sugar companies (Mukhwana and Chang'ach, 2017). In western Kenya, sugarcane transportation is dominated by tractors, tracks, trailers and grabbers (Mukhwana, 2013; Butunyi and Otieno, 2009). Ideally, sugarcane should be transported immediately after harvesting. This ought to be done efficiently and effectively to avoid sugarcane wastage through spillages, loss of sucrose content after harvesting and drying up of the harvested sugarcane while still on the farm.

Initially in western Kenya, private sugarcane once harvested stayed on the farm for three days before transportation to the sugar factories and companies while for the contracted sugarcane it took up to a week and lately can last even two weeks after harvesting (Amadala, 2020). The reason for the delayed transportation of contracted sugarcane exemplified by Mumias Sugar Company and Nzoia Sugar Company were the companies' poor harvesting programme. Just like for land preparation and input supply, Mumias Sugar Company and Nzoia Sugar Company had sub-contracted independent transporters to transport farmers the harvested sugarcane (Mukhwana, 2013). Given that two sugar companies (Mumias Sugar Company and Nzoia Sugar Company) enjoyed sugarcane supply from an expansive region, the twenty-two contracted transporters by Mumias Sugar Company for instance were unable to handle their work effectively and efficiently (Mukhwana, 2013). The justification was that Mumias Sugar Company harvested more sugarcane in different far flanged zones, making transport logistics of the farmers' harvested sugarcane more complicated. The crippling transport section especially in public sugar companies as demonstrated by Mumias Sugar Company minimized the chances of quality returns for the sugarcane farmers in western Kenya. This is because sugarcane dried up on the farms after harvesting, which made the sugarcane to lose weight and yet farmers are paid per tonnage weight of their harvested and successfully transported sugarcane to the sugar company.

In addition, this particularly for the public sugar companies, affected the sugarcane harvesters as they were also paid per ton harvested and successfully delivered to the company (Mukwana, 2016). The reduced tonnage adversely affected the sugarcane farmers' returns. Generally, transport charges across the western sugar belt increased per effectively transported ton over the years. This in reality ravaged the farmers' sugarcane returns leaving them with peanuts from their sugarcane farming efforts. The transportation costs as indicated in Table 1 were in line with the sugar companies' objective of operating at a profit.

Table 1 provides insights into the behavior of how sugar companies in western Kenya and the transporters are exorbitantly exploiting the sugarcane farmers in the region. However, there was a slight drop in the cost of effectively transporting a ton of harvested sugarcane in 2004 which can be attributed a new government regime after the 2003 general elections in the country (Mukhwana, 2013). Cumulatively, sugarcane transport for the contracted sugarcane costed more than one third of the revenue from the harvested sugarcane which depleted the sugarcane farmers' returns as tabulated in Table 2. 
Table 1. Mumias Sugar Company charges per effectively transported ton of sugarcane.

\begin{tabular}{lccccccccc}
\hline Year & 1990 & 1992 & 1994 & 1996 & 1998 & 2002 & 2004 & 2008 & 2010 \\
Ksh/Ton & 115 & 169 & 408 & 408 & 442 & 580 & 489 & 629 & 799 \\
\hline
\end{tabular}

Source: Mumias Sugar Company (MSC), Zone $(Z)=3$, Field Number $(F / N)=34 /$ Zone $(Z)=2$, Field Number $(F / N)=77 /$ Zone $(Z)=2$, Field Number $(F / N)=70 /$ Zone $(Z)=3$, Field Number $(F / N)=46$.

Table 2. A comparison of transport cost with gross income for sugarcane farmers in western Kenya.

\begin{tabular}{lccccccc}
\hline Year & $\mathbf{1 9 9 0}$ & $\mathbf{1 9 9 2}$ & $\mathbf{1 9 9 3}$ & $\mathbf{1 9 9 5}$ & $\mathbf{1 9 9 7}$ & $\mathbf{2 0 0 4}$ & $\mathbf{2 0 1 0}$ \\
\hline Gross Income & 1289645 & 1052875 & 1374288 & 2552188 & 3225944 & 2803099 & 4243750 \\
Transport Cost & 366195 & 282438 & 369404 & 670503 & 847506 & 761461 & 1077115 \\
Percentage & $28.4 \%$ & $26.8 \%$ & $26.9 \%$ & $26.3 \%$ & $26.3 \%$ & $27.2 \%$ & $25.4 \%$ \\
\hline
\end{tabular}

Source: Mumias Sugar Company (MSC), Zone $(Z)=3$, Field Number $(F / N)=34$.

Table 2 demonstrates that sugarcane transportation through time is the most expensive exercise that the sugarcane farmer has to contend with. This burden challenged the sugarcane farmers and they endured it in silence. In effect, the burden adversely affected the sugarcane farmers' returns while the sugar companies maximized on the profits as per their object. The sugarcane transportation burden compounded by delayed sugarcane transportation from the farms occasioned the sugarcane farmers in western Kenya to poach/re-direct contracted sugarcane and sell it to different companies especially the private sugar companies (Sugar Taskforce Report, 2019). Comparatively, the transport cost for the private companies like West Kenya Sugar company to Mumias Sugar Company are cheaper (Table 3).

This comparative analysis explains why West Kenya Sugar company and Butali sugar company are quickly gaining popularity in the region. Besides the transport costs, the two private players (Butali sugar company and West Kenya sugar company) in the western Kenya sugar economy are proving to be the most efficient and effective in their sugarcane transportation section in the region. This is explained by the fact that the loading of the harvested sugarcane is manual; meaning the harvested sugarcane was manually arranged and stack on their tracks and carefully tied (Mukhwana, 2013). This indeed minimized sugarcane spillage on the way to the sugar factories reducing the farmers loss of tonnage weight. This ensured that the farmers got the worth of their efforts. For Mumias Sugar Company and Nzoia Sugar Company sugarcane was carelessly packed and overloaded into tracks by grabbers (Mukhwana, 2013) that caused maximum spillage on the way to the respective sugar companies leading the farmers to lose more tones whose returns would have otherwise been used to beef up the farmers' returns.

Numerous factors were responsible for the escalating sugarcane transport costs in western Kenya. The
Table 3. Comparative tonnage transport cost in western Kenya.

\begin{tabular}{lccc}
\hline Company & $\mathbf{2 0 0 4}$ & $\mathbf{2 0 0 6}$ & $\mathbf{2 0 1 0}$ \\
\hline Mumias & 489 & 549 & 799 \\
West Kenya & 424 & 424 & 600 \\
\hline
\end{tabular}

Source: Mumias Sugar Company (MSC), Zone $(Z)=2$, Field Number $(F / N)=70 /$ Zone $(Z)=3$, Field Number $(F / N)=46$ and Account Number (A/C No) H0637.

expansiveness of the region meant that sugarcane farmers were far and wide spread from the sugar companies. Yet, the sugar companies charged the successfully transported sugarcane per ton per kilometer. Second, the western region predominantly rode on marram roads and with the region's sugarcane potential, the roads were impassable during the rainy seasons (Butunyi and Otieno, 2009). In addition, the global escalating prices of petroleum products in the world capitalist economy and the political instability in oil producing countries like Libya (Mukhwana, 2013), caused the upsurge in the sugarcane transport costs in western Kenya. Moreover, sugar companies were directly and indirectly responsible for the increased transport costs in the area. Exemplified by Mumias Sugar Company, the poor sugarcane harvesting programme where they harvested more sugarcane in different zones within the region than contracted sugarcane transporter could manage effectively and efficiently (Chege, 2005). The high demand for transporting the harvested sugarcane was sufficient reason for the transporter to hike the price of transport per ton of effectively transported sugarcane. Finally, the sugarcane farmers suffered from the burden of sugarcane transportation due to the reluctance of sugar companies to implement section 29 of the Sugar Act of 2001 (Mukhwana, 2013). This unilaterally placed the responsibility of sugarcane transportation on the sugar companies. With these factors, the sugarcane transport costs ate into the sugarcane farmers returns. 
Sugarcane transportation was a burden to the farmers that claimed the lion's share of the farmers' returns from sugarcane farming.

\section{REMUNERATIONS AND DEDUCTIONS ON SUGARCANE IN WESTERN KENYA}

The sugarcane the transport section through the transporters delivers the effectively transported sugarcane at the respective sugar companies' weigh bridge for the determination of the actual weight of the sugarcane delivered. At the weigh bridge, the net weight of the delivered sugarcane was established for the purposes of remunerating the people involved in the sugarcane production cycle (Mukhwana, 2013). The net weight of the sugarcane was used to calculate the farmers' net income for their crop. Therefore, contract and private sugarcane must be weighed on delivery to the sugar company. After the net weight of the delivered sugarcane is determined, the sugarcane farmers' gross income is calculated. The sugar company thereafter made deductions from the gross income to arrive at the farmers' net income. The deductions for the contracted farmer include: land preparation costs (surveying, ploughing, first and second furrowing and harrowing), inputs advances by the contracting sugar company, (seed cane and fertilizer) and the cost of harvesting and transportation of sugarcane to the contracting company (Mukhwana, 2013). Moreover, the company deducts levies, cess, out growers company levy (Sugar Taskforce Report, 2019), supervision (zonal manager, field clerks, and assistant clerks). In addition to shares and retention charges, the sugar company charged interest on all the services rendered. This confirms sugarcane farming as fully commercialized, for sugar companies operated on a profit-making basis to the neglect of cooperate social responsibilities. Besides, the sugarcane farmers directly met the cost of weeding and planting. The private sugarcane farmers on their part evaded deductions of land preparation, input advances and harvesting charges as they met these directly on their own without involving any sugar company (Mukhwana, 2013).

In line with the commercial objective of the sugar companies to earn profits, the rates of deductions are exorbitant as shown in Table 4.

Besides the high cost of seed-cane, fertilizer, land preparations, harvesting and transportation, the deductions eat into the sugarcane farmers' income. Sugarcane farming in western Kenya as the table indicates is commercialized and the companies earn interests from it. Occasionally, the interest rates were not revealed to the sugarcane farmers (Mukhwana, 2013), which gave the sugar companies the unilateral freedom to increase the hidden charges in order to minimize the farmers' net income. This limited one of the sugar companies' goal of providing a source of cash income to the sugarcane farmers. In fact, some farmers were
Table 4. Mumias Sugaar Company rates of deduction per ton of delivered sugarcane.

\begin{tabular}{lc}
\hline Deductions & Ksh/Ton \\
\hline Levy & 6.00 \\
Cess & 0.01 \\
Supervision & \\
Manager & 7.50 \\
Clerks & 7.50 \\
Field & 7.50 \\
Assistant & \\
MOCO & \\
Retention & $15 \%$ \\
Shares & $10 \%$ \\
Interest & $16 \%$ \\
\hline \multicolumn{2}{l}{ Source: Zone $(Z)=2$, Field Number $(\mathrm{F} / \mathrm{N})=77 /$} \\
Zone $(\mathrm{Z})=2$, Field Number $(\mathrm{F} / \mathrm{N})=70$.
\end{tabular}

deducted for shares they were oblivious of. The cess and levy that was supposed to improve the sugarcane producing locality did not serve the purpose as the infrastructure in the region was dilapidated (Sugar Taskforce Report, 2019). The failure to improve the infrastructure was technically used to hike the transport cost which provided the commercial strategy to the sugar companies to get more money from the sugarcane farmers.

In addition, an insight into the table reveals that deductions were made per ton delivered, which implies that each individual cane delivered contributes to these deductions. However, this is not practically possible in sugarcane management as the zonal managers, field clerks and their assistants did not pay attention to each individual cane on the farm. Paradoxically, farmers recounted how supervisors rarely visited their farms and if they did, they just passed by with little attention if any to their sugarcane plantations. This meant that farmers paid for services not rendered by the sugar companies officials which negatively affected the quality of sugarcane production.

In the formative years of sugarcane production in western Kenya, most Mumias Sugar Company and Nzoia Sugar Company farmers got a net income of a 'DR'. A 'DR' is a debit to the sugarcane farmers which meant that the respective sugarcane farmers were indebted to/owed the sugar company. In practical financial terms, the farmers had no cash income from their harvested sugarcane, if anything they were supposed to pay the sugar company as the company deductions exceeded the farmers' gross income. A former Mumias Sugar Company/Mumias Out-growers Cooperative's senior employee revealed that the 'DR' had two advantages on the side of the company. First, it was a net for trapping farmers to produce sugarcane for the company. Second, it was to be a catalyst that would make the sugarcane farmer to expand the acreage of land under sugarcane to 
offset their debts. The 'DR' was, therefore, a commercial innovative way by sugar companies to entrench sugarcane farming in the region.

Until the early 1990s, sugarcane payment after harvesting and delivery to Mumias and Nzoia sugar companies took three-four months on average. The sugarcane farmers indicated that they received their pay when weeding the subsequent ratoon (MSC, $Z=3$, $\mathrm{F} / \mathrm{N}=34$ ). However, from the late 1990s, farmers began receiving their dues in a month's time and in the 2000s they received it in a week's time (MSC, $Z=3, F / N=34$ ). This was courtesy of the sprouting private companies that led to competition for sugarcane in the region.
Notwithstanding the short period taken to pay the farmers, the farmers' payment record revealed that deductions claimed more than half of their gross income (MSC, $Z=3, F / N=34$ ), making them to earn peanuts after close to two years of labouring in the sugarcane plantation. This is in line with the commercial exploitative nature of sugar companies as in Table 5.

Table 5 reveals that much of the sugarcane farmers' expected returns were swindled away by the sugar companies. Although sugarcane farming provides a lump sum amount at once, the anticipated lucrative sugarcane farming venture should be engaged in with a fall back plan to supplement and complement it.

Table 5. Farmers' net income after deductions.

\begin{tabular}{lccccccccccc}
\hline Year & $\mathbf{1 9 9 0}$ & $\mathbf{1 9 9 2}$ & $\mathbf{1 9 9 3}$ & $\mathbf{1 9 9 5}$ & $\mathbf{1 9 9 7}$ & $\mathbf{1 9 9 9}$ & $\mathbf{2 0 0 1}$ & $\mathbf{2 0 0 4}$ & $\mathbf{2 0 0 5}$ & $\mathbf{2 0 0 8}$ & $\mathbf{2 0 1 0}$ \\
\hline G.I & 1289645 & 1052875 & 1374288 & 2552188 & 3225944 & 316521 & 137342 & 2803099 & 58552 & 169186 & 4243750 \\
N.I & 572533 & 433366 & 594936 & 1182020 & 1399860 & 119431 & 66408 & 1272891 & 31629 & 69722 & 2435067 \\
$\%$ & $44.4 \%$ & $41.2 \%$ & $43.3 \%$ & $46.3 \%$ & $43.4 \%$ & $37.7 \%$ & $48.4 \%$ & $45.4 \%$ & $54.0 \%$ & $10.0 \%$ & $57.4 \%$ \\
\hline
\end{tabular}

Source: Mumias Sugar Company (MSC), Zone $(\mathrm{Z})=3$, Field Number $(\mathrm{F} / \mathrm{N})=34 /$ Zone $(\mathrm{Z})=2$, Field Number $(\mathrm{F} / \mathrm{N})=77 /$ Zone $(\mathrm{Z})=2$, Field Number $(F / N)=70 /$ Zone $(Z)=3$, Field Number $(F / N)=46$.

\section{CONCLUSION}

The study examined why the heavy presence of the sugar factories in western Kenya region has not translated into full blown industrialization and sugarcane farmers' financial self-sufficiency, despite the region's availability of adequate and productive land for sugarcane farming. It further examined why the sugarcane farmers are increasingly exhibiting the sugarcane withdrawal syndrome in the region. The study concluded that the rapid desertion of sugarcane farming by sugarcane farmers in western Kenya region is ascribed to the exorbitant transport cost and lately the infiltration of weighbridges and the transport section by cartels that frustrate sugarcane farmers leaving them with no option than to abandon sugarcane farming.

\section{REFERENCES}

Amadala, B (2020). Sugarcane Farmers Need More Money to Revive Dying Mills. Daily Nation, $9^{\text {th }}$ June, 2020.

Barclay, A. H. (1997). The Mumias sugar project: A study of rural development in western Kenya. PhD Thesis, Colombia University

Butunyi, C., and Otieno, E. (2009). Sugar Shortage Hits the Market as Cane Dries Up on Farmers. Daily Nation, $10^{\text {th }}$ September, 2009.

Chege, K. J. (2005). Refining the Kenyan Sugar Industry. Daily Nation, $1^{\text {st }}$ March, 2005.

Diaz, J. A., and Perez, I. G. (2000). Simulation and optimization of sugar cane transportation in harvest season. In: Joines JA, Barton RR, Kang K, Fishwick PA, editors. Winter Simulation Conference.

Hansen, A. C., Barnes, A. J., and Lyne, P. W. L. (1998). An integrated approach to simulation sugarcane harvest-to-mill delivery. Paper presented at the 1998 ASAE Annual International Meeting
Presentation, Paper No.986099.

Heyer, J., Maitha, J. K., and Senga, W. M. (eds) (1976). Agricultural Development in Kenya. An Economic Assessment. Nairobi, Oxford University Press.

Higgins, A. J., and Muchow, R. C. (2003). Assessing the potential benefits of alternative cane supply arrangement in the Australian sugar industry. Agricultural Systems [serial online].

https://knoema.com/atlas/topics/Agriculture/Crops-Production-Quantitytonnes/Sugar-cane-production

Makana, E. N. (2008). Transformation of the Peasant Sector: The Missing Link in African Economic Development. International Journal of Sustainable Development, 1(2).

Muchow, R. C., Higgins, A. J., Rudd, A. V., and Ford, A. W. (1998). Optimising harvest date in sugar production: A case study for the Mossman mill region in Australia II. Sensitivity to crop age and crop class distribution. Field Crops Research, 57.

Mukhwana, M. D. (2013). Producing Sugar to Buy Hunger: The Contradiction of Sugarcane Production amidst Acute Subsistence Crisis in Navakholo Division, Kenya. 1970-2010. M. Phil Thesis, Moi University.

Mukhwana, M. D., and Chang'ach, J. K. (2017). The Procurement, Management and Utilization of Labour Before and After the Introduction of the Sugar in Kakamega. Asia Pacific Journal of Academic Research in Social Sciences, Vol. 2, November 2017.

National Sugar Taskforce Report (2019). Sugar Industry Stakeholders Taskforce Report. Nairobi: Government Printer.

Van Vliet, A., Boender, C. G. E., and Rinnooy Kan A. H. G. (1992). Interactive optimization of bulk sugar deliveries. Interfaces, May June, 22(3).

Walton, J. (2020). The 5 Countries That Produce the Most Sugar. https://www.investopedia.com/articles/investing/101615/5-countriesproduce-most-sugar.asp.

www.allafrica.com/modules/canetransportation.

Citation: Duncan, M. (2021). Transportation: The un-slayed dragon in sugarcane farming in Western Kenya. Net Journal of Social Sciences, 9(1): 11-16. 